\title{
Investigation the correlation between stuttering severity and inflectional morphemes stuttered in stutterers with mild to moderate severity
}

\begin{abstract}
Purpose: The purpose of this study was to investigate the relationship between stuttering severity and inflectional morphemes stuttered in 15-35 year-old stutterers with mild to moderate severity.

Method of Analysis: 20 stutters were randomly recruited (10 with a mild stuttering problem and 10 with a moderate one). Participants' speech was recorded during reading a text (about 400 syllables) in a natural setting for 3-5 minutes. Then the speech was analyzed and types of inflectional morphemes stuttered were identified. Stuttering severity was also measured utilizing the SSI-4 scale.

Findings: Data analyses indicated that there is a direct, significant and linear relationship between moderate stuttering severity and inflectional morphemes in particular types of verb prefixes $(\mathrm{r}=.671, \mathrm{p}=.024)$, and there is a direct and linear relationship between mild stuttering severity and inflectional morphemes in type of verb prefixes $(r=.249, p=.008)$, whereas this relationship was not statistically meaningful $(\mathrm{p}<.05)$. There is no meaningful statistical relationship between mild to moderate stuttering severity and inflectional morphemes (i.e., plural, indefinite, comparative and superlative, transient maker and identity verbs $)(\mathrm{p}<.05)$.

Conclusion: Results demonstrated a reduction in stuttering severity in inflectional morphemes (as a result of the low length, meaning and complexity of words) and no meaningful statistical relationship between stuttering severity (mild and moderate) and inflectional morphemes.
\end{abstract}

Keywords: stuttering, inflectional morphemes, speech disorders

\section{Introduction}

Stuttering is a type of speech fluency disorder characterized by a disruption during the normal flow of speech. The most common symptoms known for such a problem are sudden and abnormal interruptions caused with repeated, pulled and locked speech sounds. ${ }^{1,2}$ Research has reported $1 \%$ overall prevalence of stuttering which is more common in youth and decreases by aging. ${ }^{4}$ Stuttering prevalence is different in various societies. ${ }^{3}$ The occurrence of stuttering in adults is estimated by $1 \%$ being evident more in men than in women. ${ }^{5}$ Despite the high prevalence, stuttering can be considered as one of the most unknown speech disorders. ${ }^{6-9}$ Language is the major one. ${ }^{10}$

With a better understanding of stuttering and the factors affecting its formation, incidence, and prevalence, therapeutic approaches can be established according to its nature. For this reason, it is of great interest to investigate linguistic factors that may affect stuttering including word types, meaning, syntactic structure, syntactic complexity, length, syllabic structure and word loading data which have been examined in various studies. ${ }^{11-14}$ Dworzynski et al. ${ }^{15}$ Stated that the occurrence of stuttering in conversation does not happen accidentally. ${ }^{15}$ This has called for research addressing stuttering based on linguistic features. A group of researchers has reviewed a comparative study of core vocabulary frequency in children with stuttering and those with no stuttering in primary school. They found that frequency of expressive and receptive nouns in children who stutter is significantly lower than those who do not stutter. It seems that stuttering affects the frequency of expressive and receptive vocabulary in noun category. Similar findings were reported for the
Volume 4 Issue I - 2019

\section{Fatemeh Khebri, Hamide Ghaemi, Maryam Mohammad zadeh, Leyla Ezazi, Davood Sobhani Rad}

Department Speech Therapy, School of Paramedical Sciences, Mashhad University of Medical Sciences, Iran

Correspondence: Hamide Ghaemi, Department of Speech Therapy, School of Paramedical Sciences, Mashhad University of Medical Sciences, Mashhad, Iran, Email Hamideghaemi@yahoo.com

Received: January 05, 2019 | Published: January 17, 2019 verb category suggesting that stuttering influences the verb category, too. However, the findings demonstrated that frequency of expressive and receptive vocabulary in adjective category is not significantly different between children who do not stutter and those stuttering suggesting that the frequency of expressive and receptive vocabulary in adjective category is not affected by stuttering. ${ }^{16}$

Functional and semantic morphemes in Persian words have been studied in children and adults who stutter. It appeared that stuttering pattern in functional morphemes and even the meaning of words change in different ages. This could due to the difference in the structure of functional morphemes in Persian and language planning which seems to be more difficult that it is in English. ${ }^{1}$ A study of phonological awareness in stutterer and non-stuttering children of 4 to 8 years old in Tehran suggested that factors such as phonological awareness, age, types and severity of stuttering should be considered in assessment and treatment of stuttering children. ${ }^{17}$

Deficit reported in studies of stuttering looking into the linguistic features does not appear to have divided stutterers based on the severity of their problems. In other words, the results of all participants were measured and evaluated regardless of their severity of stuttering. However, given severity of stuttering, level of processing of linguistic information is different. Furthermore, the degree of difficulty in language processing is also different. ${ }^{18}$ The current body of research in stuttering suggests that Persian speakers with stuttering demonstrate a different degree of prolongation, silence or block, at the launch and remedial review in different ages which depends on the severity of stuttering resulting from the type of sentence and verbal words (word complexity, length and information). 
Morpheme is the smallest meaningful unit of the language, a term which cannot be analyzed in terms of unit role or smaller meaningful units. A word can be made of a morpheme or combination of several morphemes. ${ }^{19}$ Persian language morphemes in the first classification could be divided into two major categories: free morphemes and dependent morphemes. Free morphemes (lexicon) may be used independently forming a simple word, or they can organize the main morpheme of a verb or non-verb. ${ }^{20}$ Unlike free morphemes, dependent morphemes are morphemes that cannot appear alone without accompanying another morpheme in a word. ${ }^{20}$

Additionally, dependent morpheme can be divided in to two categories in Persian: derivation morpheme, and inflectional morpheme. ${ }^{21}$ Derivation morphemes are merely used on a limited basis such as prefix or suffix along with certain basic free morphemes. Hence, they are called affixes, too. ${ }^{21}$ Inflectional morphemes which convey the concept of special orders (e.g., indefinite, definite, comparison, superlatives, time, collation, progressive and so on) are used as morphological prefixes or suffixes along with free morphemes of names, adjectives and adverbs or construction of verb words. These are called affixes or morphological morphemes. ${ }^{21}$ Morphological morphemes have two major features. They can be used along with all morphemes in a category or class uniformly and almost without exception, and they do not change the category of word by themselves. ${ }^{21}$

Since it is likely that people with stuttering problems demonstrate various degrees of stuttering, investigations into different types of morphemes (e.g., inflectional) may bring awareness over this issue to help identify reactions of stutterers based on the types of morphemes in Persian. Such studies are also informative in designing an appropriate treatment plan and special targets for stutterers. Additionally, it seems that research looking into the relationship between stuttering severity and the types of inflectional morphemes in stuttering is scant with no research as such being conducted in Iran among Persian speakers. The current study is an attempt to investigate such problems in a group of 15-35 years old with mild to moderate severity by considering the severity of stuttering in different morphemes. The results of this study would be beneficial for people with stuttering problems, their families and rehabilitation team to design a treatment protocol.

\section{Methods}

This study was designed for a cross-sectional comparison. The aim of the study was to investigate the relationship between stuttering severity and the types of inflectional morphemes in stutterers of 1535 years old with mild to moderate severity. The total number of population in this study was 20 people (10 with a mild stuttering problem and 10 with a moderate one). According to the study of Mokhlesin et al. ${ }^{1}$ and based on the formula estimating, one ratio (according to qualitative features of main variables) was estimated for each specific objectives measured in this study. The ratio was obtained the highest number. In this regard, some colleges and health centers (such as Ghaem Hospital, Doctor Sheikh Hospital and Imam Reza Hospital) in Mashhad were visited, and the study criteria for participants' recruitment were observed. These included stuttering severity, age range (from 15 to 35), lack of auditory and visual deficits, lack of motor skills and neurological deficits, lack of accompanied deficits including lack of attention, concentration and ADHD, lack of bilingualism, and having literacy (reading and writing) deficits. The inclusion criteria were also assessed by reviewing the participants' medical records and interviewing the individuals. Exclusion criteria were also set. Participants who did not turn up, those who did not cooperate with experimenter, and if they could not accomplish the experiment after 10 to 15 minutes were excluded from the data.

Additionally, sampling was random. Before performing the experiment, in order to build confidence and better participation, a briefing session was held on the necessity and the cause of carrying out the experiment. Then, the location of the experiment by supplying a sense of calmness and peace of mind was designated. Testing appeared in a quiet room and participants were individually tested. Participants' speech was recorded while they read a text (about 400 syllables) in a natural setting for 3-5 minutes. Then the speech was analyzed and types of inflectional morphemes stuttered were identified. Stuttering severity was also measured utilizing the SSI4 scale. Additionally, the types of inflectional morphemes stuttered were identified (i.e., plural, indefinite, comparative and superlative, transient maker and identity verbs).

\section{Results}

Since the purpose of this study was to compare the relationship between stuttering severity and the types of inflectional morphemes in stutterers at the age of 15-35 with mild to moderate severity, Spearman correlation test was conducted to determine whether a meaningful relationship could be found between stuttering severity and the type of inflectional morphemes stuttered. Table 1 presents the demographic information of the participants.

Table 1 indicates the average percentage of stuttering severity in inflectional morphemes stuttered in the spontaneous speech of stutterers. Analyzing the spontaneous speech of stutterers (10 with a mild stuttering problem and 10 with a moderate one). The data demonstrated that people with mild stuttering did not stutter in all inflectional morphemes (i.e., plural, indefinite, comparative and superlative, transient maker and identity verbs) apart from the types of verb prefixes $(0 \%)$ with an average of stuttering severity in verb prefixes being $1.27 \%$. The data also indicated that people with moderate stuttering severity were not stuttering in all inflectional morphemes (i.e., plural, indefinite, comparative and superlative, transient maker and identity verbs) apart from the type of verb prefixes $(0 \%)$ with an average of stuttering severity in type of verb prefixes being $14.77 \%$.

Table 2 presents the relationship between mild stuttering severity and the types of inflectional morphemes stuttered. The results of the Spearman correlation test showed a direct and linear relationship between mild stuttering severity and inflectional morphemes in type of verb prefixes $(\mathrm{r}=.249, p=.008)$, whereas this relationship was not statistically meaningful $(p<.05)$ and also there was no statistically a significant relationship between mild stuttering severity and other inflectional morphemes studied $(p<.05)$.

Table I The average percentage of stuttering severity in inflectional morphemes stuttered in spontaneous speech ( $\mathrm{N}=20)$

\begin{tabular}{llllll}
\hline indefinite sign & more and most sign & verb prefixes & $\begin{array}{l}\text { transient maker } \\
\text { morpheme }\end{array}$ & $\begin{array}{l}\text { Stuttering } \\
\text { severity }\end{array}$ \\
\hline $0 \%$ & $0 \%$ & $1 / 27 \%$ & $0 \%$ & $0 \%$ & $0 \%$ \\
$0 \%$ & $0 \%$ & $14 / 77 \%$ & $0 \%$ & $0 \%$ & $0 \%$ \\
\hline
\end{tabular}


Table 2 The relationship between mild stuttering severity and the types of inflectional morphemes stuttered $(\mathrm{N}=20)$

\begin{tabular}{lll}
\hline $\mathbf{r}$ & P value & Type of morpheme \\
\hline 0 & 0 & Indefinite sign \\
0 & 0 & More and most sign \\
$0 / 249$ & $0 / 008$ & Verb prefixes \\
0 & 0 & Transient maker morpheme \\
0 & 0 & Identifying verb \\
0 & 0 & Plural sign \\
\hline
\end{tabular}

As shown in Table 3, the relationship between moderate stuttering severity and the types of inflectional morphemes stuttered utilizing the Spearman correlation test showed a direct, significant and linear relationship only between moderate stuttering severity and inflectional morphemes in type of verb prefixes $(\mathrm{r}=.671, p=.024)$, whereas this relationship was not statistically meaningful $(p<.05)$ with no statistically a significant relationship between moderate stuttering severity and other inflectional morphemes studied $(p<.05)$.

Table 3 The relationship between moderate stuttering severity and the types of inflectional morphemes stuttered

\begin{tabular}{lll}
\hline $\mathbf{r}$ & $\mathbf{p}$ value & Type of morpheme \\
\hline 0 & 0 & Indefinite sign \\
0 & 0 & More and most sign \\
$0 / 671$ & $0 / 024$ & Verb prefixes \\
0 & 0 & Transient maker morpheme \\
0 & 0 & Identifying verbs \\
0 & 0 & Plural sign \\
\hline
\end{tabular}

\section{Discussion}

This study was carried out to review the relationship between stuttering severity and types of inflectional morphemes stuttered in 15-35 year-old stutterers with mild to moderate severity. Stuttering is the most common speech and language disorders. ${ }^{22}$ Stuttering is a complex disorder with psychomotor features that occurs in the natural process of speech in the form of repetition, block and prolongation. ${ }^{23}$ Extensive studies have been conducted over the impact of linguistic factors (e.g., meaningful and meaningless words, types of the words, construction and syntactic complexity of sentences, length and loading data of spoken words) on the frequency of occurrence disfluencies. For example, according to these studies, stuttering severity in stutterers on meaningless pseudo-words is much more evident than those in meaningful words.

Additionally, studies showed that there is a significant and direct relationship between length of spoken phrases and the severity of speech deficit in preschool children who stutter. Furthermore, it has been proven that age of language acquisition and variation in syntactic complexity of sentences can affect the type and severity of speech deficit. ${ }^{22-29,26}$ The findings of the current study (as presented in Table 1) showed that stutters with mild and moderate severity were not stuttering in all inflectional morphemes (i.e., plural, indefinite, comparative and superlative, transient maker and identity verbs) apart from the type of verb prefixes $(0 \%)$ and the average of stuttering severity in type of verb prefixes in those with a mild stuttering severity being $1.27 \%$ and in moderate severity being $14.77 \%$. Additionally, the findings (as presented in Table 2 and Table 3) showed that there is only a direct and significant relationship between stuttering severity (mild and moderate) and inflectional morphemes in types of verb prefixes, whereas this relationship was not statistically meaningful $(p<.05)$ and there was not statistically a significant relationship between stuttering severity (mild and moderate) and other inflectional morphemes studied (i.e., plural, indefinite, comparative and superlative, transient maker and identity verbs) $(p<.05)$. These findings are consistent with the findings reported by Throneburg et al. ${ }^{24}$ who studied the relationship between phonological awareness deficits and the occurrence of fluency deficits in the early stages of stuttering. Their findings suggested that there is a significant positive correlation between severity of fluency deficit and the types of words with any phonological difficulties causing an increase in stuttering severity. ${ }^{24}$ These findings are also aligned with the findings of the study reported by Soderberg ${ }^{25}$ related to word information and word length with stuttering fluency deficit. The results suggested that word information and word length are independently associated with stuttering severity. That is when word information and word length increase, fluency deficit also increases. ${ }^{25}$

The findings are also consistent with the findings of the findings reported by Masumi et al. ${ }^{22}$ who investigated the effect of word meaning on speech disfluency in adults with developmental stuttering. The results of their study showed that frequency of speech disfluency in pseudo-words is significantly more than that in words. ${ }^{22}$ These findings are in line with most studies over the effect of the complexities of lingual syntactic on speech fluency deficit. For example, in two separate studies, it was found that enhancing the length and complexity of the speech in children with stuttering problems can increase the number and intensity of speech fluency deficit. ${ }^{30,31}$

Generally, the results of the current study showed that in inflectional morphemes except the verb prefixes, stuttering severity is close to zero. Such findings could be as a result of the difficulty, complexity, length and information in all inflectional morphemes except the verb prefixes which seems to be too low which makes stuttering severity so poor. The findings showed that stuttering severity can be an important factor in influencing linguistic factors. It can be suggested that by development of mild to moderate stuttering severity, linguistic factors (i.e., types of language functions) will have a greater impact on the severity of symptoms and children's deficit in fluencies in such a way that the language function of a difficult task with greater complexity (such as pattern of sentence composition functions) being affected. Hence fluency deficit increases in this situation. According to some researches, the level of complexity processing in pattern of sentence composition is higher than those in sentence imitation tasks. ${ }^{26,27}$ The results of this study suggested that speech and language pathologists assessing and planning therapeutic processes in people who stutter should consider the impact of linguistic factor. ${ }^{22}$ It also suggested those who are interested in the area of research should work on the impact of free morphemes in stuttering severity.

In fact, a deficit is evident in all studies reported due to lack of separating stutterers studied. That is the two distinct groups based on their stuttering severity have never been separated. ${ }^{32}$ Thus, the current study was an attempt to separate cohorts based on their stuttering severity. The limitations of this study can be pointed out as the lack of cooperation of the participants, a limited number of participants and limited access to various genders (i.e., male and female).

\section{Conclusion}

According to the results reported, severity of stuttering from mild and moderate is generally very low (except in verb prefixes which is close to zero) in inflectional morphemes compared to other words. His 
could be due to the difficulty, complexity, length and meaning of the inflectional morphemes which seems to be lower than those in other types of words suggesting that there is no statistically a significant relationship between stuttering severity (mild and moderate) and inflectional morphemes. This is a highly important findings for clinicians and therapists assisting them to make more informed decisions and planning for their assessments and treatments.

\section{Acknowledgments}

The researchers appreciate respected participants from the Imam Reza Hospital, Doctor Sheikh Hospital, Ghaem Hospital for their friendly cooperation in the process of this research.

\section{Conflicts of interest}

The authors declare no conflict of interest.

\section{References}

1. Mokhlesin M, Shahbodaghi MR, Ahadi H, et al. Comparison of functional words and meaning between children and adults stutter in Persian. Journal of Cognitive Science News. 2007;9(3):45-51.

2. Shafiei B, Mehralian Z. Nonfluency disorder in children. 2nd ed. Isfahan: Isfahan University of Medical Sciences; 2006.

3. Bloodstein O, Nan Ratner B. A handbook on stuttering. 6th ed. Ckitfon Park. NY: Cangage Publishing; 2007:211-220.

4. Guitar B. Stuttering: An integrated approach to its nature and treatment 3rd ed. Philadelphia, Lippincott Williams\& Wilkins Pub, 2006;19:187192.

5. Bloodstein O, NB Ratner. A handbook on stuttering, Thomson Delmar Learning; 2008.

6. Mohammadi H, Nilipour R, Yadegari F, et al. Prevalence of stuttering in javanrud's bilingual students. J Rehabilitation. 2008;9(1):43-48.

7. Shahbodaghi MR. Prevalence of Speech and language disorders in preliminary degree girls' students. J Rehabilitation. 2000; 11(4):20-26.

8. Naseh H. The survey of speech disorders in clients to amuzeshvaparvaresh clinic of bandar-abbas city in 1383-84. Hormozgan Med J. 2004;10(3):274-278.

9. Zamani P, Ravanbakhsh M, Naderi S. Preschoolers who stutter speech disfluencies assess the severity of the sentence imitation and such tests of the model. J ShahrekordUniv Med Sci. 2015;17(2):61-69.

10. Guitar B. Stuttering: an integrated approach to its nature and treatment 3rd ed. Philadelphia, PA: Lippincott Williams \& Wilkins; 2006.

11. Brown SF, Moren A. The frequency of stuttering in relation to word length during oral reading. Journal Speech Disorders. 1942; 7(2):153159.

12. Smith A, Sadagopan N, Walsh B, et al. Increasing phonological complexity reveals heightened instability in inter-articulatory coordination in adults who stutter. J Fluency Disord. 2010;35(1):1-18.

13. Richels $\mathrm{C}, \mathrm{Buhr} \mathrm{A}$, Conture $\mathrm{E}$, et al. Utterance complexity and stuttering on function words in preschool- age children who stutter. J Fluency Disord. 2010;35(3):314-331

14. Dayalu VN, Kalinowski J, Stuart A. Stuttering frequency on meaningfu and non-meaningful words in adults who stutter. Folia phoniatrLogop. 2005;57(4):193-201.
15. DworzynskiK, Howell P. Predicting stuttering from phonetic complexity in German. J Fluency Disord. 2004;29(2):149-173.

16. Sakhaei F, Shahbodaghi MR, Faqihzadeh S, et al. A comparative study of core vocabulary frequency in children who stutter and who do not stutter in primary school. Journal of modern rehabilitation. 2009;2(3 and 4): $12-18$

17. Ghaffari z, Shahbodaghi MR, jalali SH. Evaluation of phonological awareness in stutterer and non-stutterer children of aged 4 to 8 years in Tehran. (Audiology) auditory and Vestibular research. 2012;21(2):3841.

18. Gordon PA. Language task effects: A comparison of stuttering and nonstuttering children. J Fluency Disord. 1991;16(5):275-287.

19. Katamba F, Stonham J. Morphology. 2nd ed. Pagrave Macmillan; 2006.

20. Gholamalizade KH. Construction of Persian language. 1st ed. Tehran: Ehya book Publishers; 1995.

21. Meshkodini M. Persian grammar: vocabulary and structural links. 1nd ed. Tehran: Organization of study and codification of Humanities Books universities (SMT); 2005.

22. Masumi E, AraniKashani Z, Ghorbani A, et al. The effect of word meaning on speech dysfluency in adults with developmental stuttering. Journal of Rehabilitation Sciences. 2013;9(4):705-714.

23. Howell P. Signs of developmental stuttering up to age eight and at 12 plus. ClinPsychol Rev. 2007;27(3):287-306.

24. Throneburg R, Yairi E, Elaine P. Relation between phonologic difficulty and the occurrence of disfluencies in the early stage of stuttering. Journal of Faculty Research and Creative Activity. 1994;9(3):6-13.

25. George A, Soderberg. Relations of word information and word length to stuttering disfluencies. Journal of Communication Disorders. 1971;4(1):9-14.

26. Buhr A, Zebrowski P. Sentence position and syntactic complexity of stuttering in early childhood: a longitudinal study. J Fluency Disord. 2009;34(3):155-172.

27. Melnick KS, Conture EG. Relationship of length and grammatical complexity to the systematic and nonsystematic speech errors and stuttering of children who stutter. J Fluency Disorder. 2000;25(1):2145 .

28. Zackheim CT, Conture EG. Childhood stuttering and speech disfluencies in relation to children's mean length of utterance: a preliminary study. $J$ Fluency disorder. 2003;28(2):115-141.

29. Richels C, Buhr A, Conture E, et al. Utterance complexity and stuttering on function words in preschool-age children who stutter. J Fluency disorder. 2010;35(3):314-331.

30. Sawyer J, Chon H, Ambrose NG. Influences of rate, length, and complexity on speech disfluency in a single-speech sample in preschool children who stutter. J Fluency disorder. 2008;33(3):220-240.

31. Maner KJ, Smith A, Grayson L. Influences of utterance length and complexity on speech motor performance in children and adults. $J$ Speech Lang Hear Res. 2000;43(2):560-573.

32. Zamani P, Naderifar E, Latifi M. Effect of prolonged speech technique in reducing stuttering persian-speaking people with severe stutter. Journal of Tabriz University of Medical Sciences. 2012;34(3):64-48. 